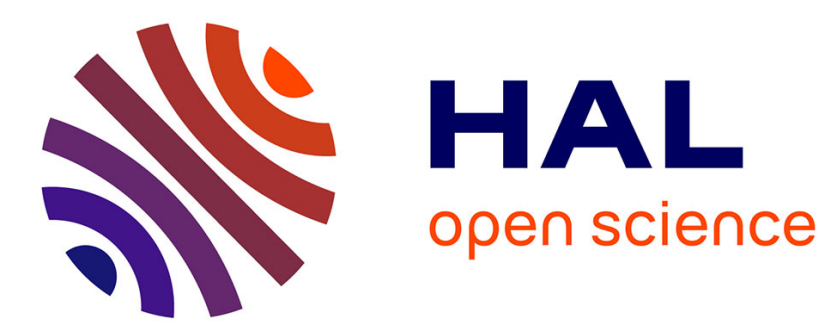

\title{
Graph-based reasoning in collaborative knowledge management for industrial maintenance
}

Bernard Kamsu-Foguem, Daniel Noyes

\section{To cite this version:}

Bernard Kamsu-Foguem, Daniel Noyes. Graph-based reasoning in collaborative knowledge management for industrial maintenance. Computers in Industry, 2013, Vol. 64, pp. 998-1013. 10.1016/j.compind.2013.06.013 . hal-00881052

\section{HAL Id: hal-00881052 \\ https://hal.science/hal-00881052}

Submitted on 7 Nov 2013

HAL is a multi-disciplinary open access archive for the deposit and dissemination of scientific research documents, whether they are published or not. The documents may come from teaching and research institutions in France or abroad, or from public or private research centers.
L'archive ouverte pluridisciplinaire HAL, est destinée au dépôt et à la diffusion de documents scientifiques de niveau recherche, publiés ou non, émanant des établissements d'enseignement et de recherche français ou étrangers, des laboratoires publics ou privés. 


\section{Open Archive Toulouse Archive Ouverte (OATAO)}

OATAO is an open access repository that collects the work of Toulouse researchers and makes it freely available over the web where possible.

This is an author-deposited version published in: http://oatao.univ-toulouse.fr/ Eprints ID: 9587

To link to this article: doi.org/10.1016/j.compind.2013.06.013 http://www.sciencedirect.com/science/article/pii/S0166361513001279

\section{To cite this version:}

Kamsu Foguem, Bernard and Noyes, Daniel Graph-based reasoning in collaborative knowledge management for industrial maintenance. (2013) Computers in Industry, Vol. 64 . pp. 998-1013. ISSN 0166-3615 


\title{
Graph-based reasoning in collaborative knowledge management for industrial maintenance
}

\author{
Bernard Kamsu-Foguem*, Daniel Noyes \\ Laboratory of Production Engineering (LGP), EA 1905, ENIT, INPT, University of Toulouse, 47 Avenue d'Azereix, BP 1629, 65016 Tarbes Cedex, France
}

\begin{abstract}
A B S T R A C T
Capitalization and sharing of lessons learned play an essential role in managing the activities of industrial systems. This is particularly the case for the maintenance management, especially for distributed systems often associated with collaborative decision-making systems. Our contribution focuses on the formalization of the expert knowledge required for maintenance actors that will easily engage support tools to accomplish their missions in collaborative frameworks. To do this, we use the conceptual graphs formalism with their reasoning operations for the comparison and integration of several conceptual graph rules corresponding to different viewpoint of experts. The proposed approach is applied to a case study focusing on the maintenance management of a rotary machinery system.
\end{abstract}

Keywords:

Experience feedback

Conceptual graph rule

Expert knowledge

Maintenance management

Case-based reasoning

Fleet considerations

\section{Introduction}

The capitalization of the expertise is now a critical issue for industrial businesses facing the demographic changes in staffing levels and the valuation problems of intangible assets (business reputation, trained workforce, and noncompetition agreements). At the maintenance function, technological and organizational developments force internal and external collaborations to ensure local and global performance of that maintained system [1]. We find this situation in socio-technical, networked and distributed systems (communication, power, transportation, etc.), for which the resources and maintenance skills are also very often distributed, with an increasing reliance on technological network systems [2]. Other emerging collaborative networks are developed by human professionals that may collaborate in virtual communities and constitute virtual teams to deal with specific problems or concerns, and find paths to breakthrough successes [3]. Problems concerning the exploitation of individual practices are sometimes based on the management and the structuring of shared information by a collective [4].

Maintenance activities involve so often collaborative actions and decision-making in which groups of actors are working together through a common area of problem solving [5]. The

\footnotetext{
* Corresponding author. Tel.: +33 624302337/562442718.

E-mail addresses: bernard.kamsu-foguem@enit.fr (B. Kamsu-Foguem), Daniel.Noyes@enit.fr (D. Noyes).
}

conceptualization of the mechanisms involved in these collaborative exchanges facilitates the integration of knowledge management in collaborative decision-making systems [6]. The research on collaborative decision-making in maintenance management has highlighted the information needs for problem-solving methods but few integrate the aspect of knowledge management [7]. Tools are available at this level [8,9] but they often require a suitable knowledge formalization so they can be shared in a context, which moved from reactive centralized processing architectures, to distributed intelligent infrastructures. Moreover, the deployment of a sustainable action plan for risk management requires the integration of know-how and contextualized experiences to develop and implement appropriate maintenance policies [10]. Historically, Experience Feedback (EF) was mainly based on statistical methods to identify some failure laws. However, this kind of feedback does not allow the extraction of expert knowledge from the technical data. This is made possible by the "cognitive approach" of experience feedback modeling. It models the expert knowledge of the organization and facilitates the enrichment of knowledge repository by using methods from artificial intelligence. Intelligent data analysis and data mining support the extraction of patterns and regularities from the process data collected during maintenance activities $[11,12]$. The transformation of such patterns into explicit knowledge requires knowledge representation formalisms and tools. The cognitive vision framework of experience feedback provides means of understanding, interpreting, storing and indexing the activities of experts [13]. EF applied to the maintenance management takes place as continuous 
improvement that emphasizes the ongoing monitoring and verification of the root causes of problems in the monitored system to eliminate repetitive failures and recurring problems [14]. The approach proposed in this work is based on the EF exploitation in collaborative decision-making situations. The goal is to improve collaboration among maintenance actors by the deployment of knowledge engineering tools to effectively share experiences, generating knowledge to better resolve problems. The approach of dynamic capitalization of knowledge supports knowledge validation process among collaborating actors, hence increasing the reliability of capitalized knowledge [15]. Problem solving will include knowledge reasoning based on the conceptual graphs (CG) formalism [16]. The choice of knowledge representation by CG should enable a better understanding of critical situations and provide assistance to the appropriate decision-making in order to anticipate them [17]. The expected result is a better use of knowledge and skills distributed among different experts: (1) strengthening the collective knowledge with the promotion of access by the collaborative actors to relevant information and the enhancement of plans for the maintenance of the target system, (2) facilitating the sustainable management of experience learning and providing support to the modeling and improvement of the quality of knowledge sharing within the collaborative organization.

The paper is structured as followed. Section 2 exposes the proposed methodology and its main components concerning knowledge engineering. Section 3 presents the cognitive experience feedback approach applied to industrial maintenance management. Section 4 presents the conceptual graphs operations used to implement the modeling of expert rules in collaborative decision-making processes. An illustrative application example for the maintenance management of a rotary machinery system from the railway field is exposed in Section 5. Finally, Section 6 concludes and discusses future challenges.

\section{Collaboration in maintenance activities: situation and requirements}

\subsection{The needs and the actors concerned}

In the context of industrial maintenance, industrial operation or industrial logistic support, simple or intelligence collaboration provides the opportunity for a new generation of maintenance systems. These systems are composed of self-ruling modules (increasingly more intelligent) interconnected by computer networks. As the networks rightly emphasizes, the functioning of the industrial maintenance is affected by the diversity, the heterogeneity and sometimes the intensification of interactive processes with less knowledge transfer of expertise. In order to work efficiently such inter professional collaboration needs to be addressed both in the information exchange and technical data processing. Threats related to the control environment include information systems complexity, timely review of collaborative results and the robustness of the principles of organization. Collaboration is needed in some maintenance activities (e.g. diagnostics, decision-making at different levels) for several motivations:

- organizations and people are essentially self-governing, geographically distributed, and heterogeneous in terms of their operating environment, beliefs and community of practices or competencies [18];

- actors collaborate to (better) achieve communication and information exchange, complementarity or compatibility of goals, aligning activities, process of shared competencies to solve a problem together;

- open source/web-based applications are the central thread of organization knowledge sharing (best practices) for efficient decision-making of which the effective assessment of alternatives is a crucial element of guaranteeing the robustness of the maintenance policies.

These industrial motivations integrate existing maintenance principles with modern Web services and the principles of collaborative networks. Collaboration is also useful for computational intelligence that needs to be fluently re-configured as guided by the requirements of tractability and agility.

Emerging collaborative maintenance networks are formed by human resources (e.g. operator, sub-contractor, maintainer and experts) that may collaborate in distributed organizations with virtual project teams. The collaborative networks are again formed by automated resources (e.g. Supervisory Control and Data Acquisition (SCADA), Computerized Maintenance Management System (CMMS), Health and Usage Monitoring System (HUMS)) and they may incorporate information technology modules such as acquisition, processing and visualization. A collaborative and userfriendly CMMS is available on the industrial applications and was developed for the technical departments mainly of production companies or companies who wish to plan the proactive maintenance of their critical equipment and machines. Moreover "automated collaboration" is advocated through "technical intelligence" collaboration implemented within HUMS, smart components (to support Integrated Vehicle Health Management (IVHM) concept for example) where it is possible to find master and slave.

A HUMS framework employs numerous sensors connected to a central data recording system, to collect quantitative data in embedded system (e.g. flight, ship) from systems and components throughout the embedded system. The data are downloaded to ground-based computers for further analysis (maintenance, cost, operational and performance). Typically, the data record the types of operations the embedded system has performed, and can be used to predict the health and remaining life of components with streamlined logistics for fleet deployment. IVHM system for aerospace vehicles, is the process of assessing, preserving, and restoring system functionality across flight and techniques with sensor and communication technologies for spacecraft that can generate responses through detection, diagnosis, reasoning, and adapt to system faults in support of Integrated Intelligent Vehicle Management (IIVM) [19]. Likewise, this framework incorporates technologies which can deliver a continuous, intelligent, and adaptive health state of an embedded system and manage this information to develop safety and reduce costs of operations. So the IVHM characterizes a logistic support for the transport process and influences its level of reliability [20]. However, there are some technical challenges (tool, platform and integration issues) and organizational challenges (structural and cultural problems) of implementing IVHM on legacy platforms. The categorization of commonest types of organizational challenges face when retrofitting IVHM has been described by a recent work [21].

\subsection{The types of collaboration and their constraints}

These human and automated actors may collaborate in virtual communities to address specific problems, such as collaborative troubleshooting or deployment of the remote assistance expertise of the organizations. This collaboration allows potential improvements in maintenance on various activities (failure analysis, documentation of maintenance, fault diagnosis/location and repair/reconstruction) that can be briefly described as follows [22]:

- Failure analysis: developments in sensor technology, signal processing, ICT (Information and Communications Technology) and other technologies related to monitoring and diagnostics 
enable stakeholders maintenance to improve understanding of the causes of the failures, faults of the system and better monitoring and signal analysis methods, materials, techniques, design and production of better quality: to move from fault detection to monitor the degradation;

- Documentation of maintenance: information such as the completion of the task can be completed once by the user and sent to multiple listeners (software or actors) that recorded for such an event. An example is the bottleneck of massive data between production systems and business management, which can now be eliminated by converting raw data of the state machine, data on the quality of products and data on the process capability in the information and knowledge for dynamic decision making;

- Fault diagnosis/location: the full implementation of web-based mechanisms provides experts to diagnose fault online with their most significant experiences, and proposes solutions to operators if an abnormal condition occurs on the equipment to inspect [23]. Feasible solution of the expert can be contextualized; quality of the shared information can be improved and, consequently, reduces the time to resolution. All these factors contribute to increasing the availability of equipment and means of production, to reduce mean time to repair (MTTR);

- Repair/reconstruction: costly system downtime and maintenance expense could potentially be reduced by direct contact and interaction (troubleshooting) with designers and specialists of the original system. For example, diagnosis, maintenance work carried out and parts replaced are documented online through structured responses in the job steps that are explicitly displayed in systems support.

Maintenance services of the industrial organizations are structured as a network of resources and competencies which are distributed among the units and domains of the engineering. Collaborative Networked Organizations (CNO) are driven or constrained by some factors such as the interoperability principles, internal association mechanisms, dynamic inter-organizational rules and goal-driven policies. The macroscopic behavior of $\mathrm{CNO}$ can only be fully understood by the description of its life cycle with the following main stages [3]: (i) creation (initiation and foundation), (ii) operation (stable functioning), (iii) evolution (minor changes) and (iv) dissolution (termination of temporal existence) or metamorphosis (major changes).

Besides, one major reason for the slack advancement in applying maintenance technologies to complex systems is the presence of uncertainty in every step of the reliability assessment process and system safety. In applications of operative maintenance systems, the sources of uncertainty may be classified into environmental and operational uncertainties (e.g. weather, loading conditions); scenario abstractions (e.g. subjective decisions, lack of knowledge); system uncertainties (e.g. non-linearity, boundary conditions, complexity); signal processing uncertainties (e.g. sensors, data fusion, decision making); and model uncertainties (e.g. form, parameters) [24].

Moreover, because of the financial considerations, it has now become the practice for a policy of task shifting that aims to entrust a less-qualified group of professionals with the tasks of a higher level group and to build their capacities through training and supervision. So less qualified workers take action at the level of routine tasks and the expert opinions and interventions of which will assist them in complex important duties. Providing expert consultations for both operators and maintainer on one site is still an interesting approach, but it is expensive and experienced knowledge is in most cases unavailable, incomplete or distributed.

We are interested in solving complex problems in maintenance and we will discuss how can be solicited and managed the knowledge of stakeholders (operators, maintainers and experts) to contribute to the improvement of the collaborative decisionmaking. Primary resources (operators and maintainers) provide the structural flexibility for the rapid and temporary deployment of maintenance actions to undertake assessment missions when a problem is detected or to monitor and advise on the implementation. Many local primary resources do not cover the complex situations that require dedicated resources and experienced actors.

Industrial organizations should reinforce their capacities in advanced activities, with a view to advanced studies, in close interaction with experts in the field of maintenance, and share their best practices together. The expert resources with sustainable methodologies can help organizations achieve measurable results and fast time to value, while addressing the middle or long term needs of complex situations. The expertise tends to be expensive and not widely available in many industrial situations. However, the longer a decision takes, the more critical it becomes. This decision-making may involve pooling of specialized resources, working collaboratively toward a similar goal, or sharing of information. It can be considered that in typical situations of maintenance activities and complex problem solving strategies, the collaboration is carried out as follows (Fig. 1):

- an actor $A_{i}$ tries to solve the problem in its own case base. If the problem solving action is unsuccessful, he broadcasts the problem to other experts who return their solution to $A_{i}$.

- the actor $A_{i}$ selects the most suitable actor $A_{j}$ for the resolution, according to an assessment calculated from the expertise and skills of different actors. Thus, $A_{i}$ obtains the solution proposed for $A_{j}$ and acts locally to solve the cases.

Patterns and processes of maintenance deployment and management will give priority to the use of alternative communication systems and access to relevant knowledge in the context of crisis management. The experts can offer organizational backup for complex maintenance and valuable local assistance in crisis situations. The introduction of common knowledge representation formalism will be very interesting to improve exchanges between distributed actors and enhance workflows understanding. The reasoning mechanisms of this formalism will be useful for mismatching detection calculations as well as for best collaborative reasoning identifications.

\section{Cognitive experience feedback for industrial maintenance management}

In general, diverse studies have concentrated on distinct features of expertise effects on cognition, including hypothesis generation and evaluation, knowledge representations underlying performance, diagnostic reasoning and the organization of decision knowledge. The development of expertise involves experience-based learning (i.e. through exposure to real situations) and each progressing phase is characterized by functionally different knowledge structures underlying performance. Additionally, to a certain degree, expert reasoning is based on the similarity between the presenting situation and some previous situations available from memory.

Often, information and maintenance data (system's states, procedures, protocols, etc.) are variously formalized and stakeholders' knowledge (business rules, normative requirements, standards, etc.) is rarely explicit, which makes them difficult to use within their immediate framework and, a fortiori, in shifted contexts. This can be critical if it relates to delocalized units, with limited means and whose experiences (past events processing) are few (resulting, for example, from distributed architectures and infrastructures). 


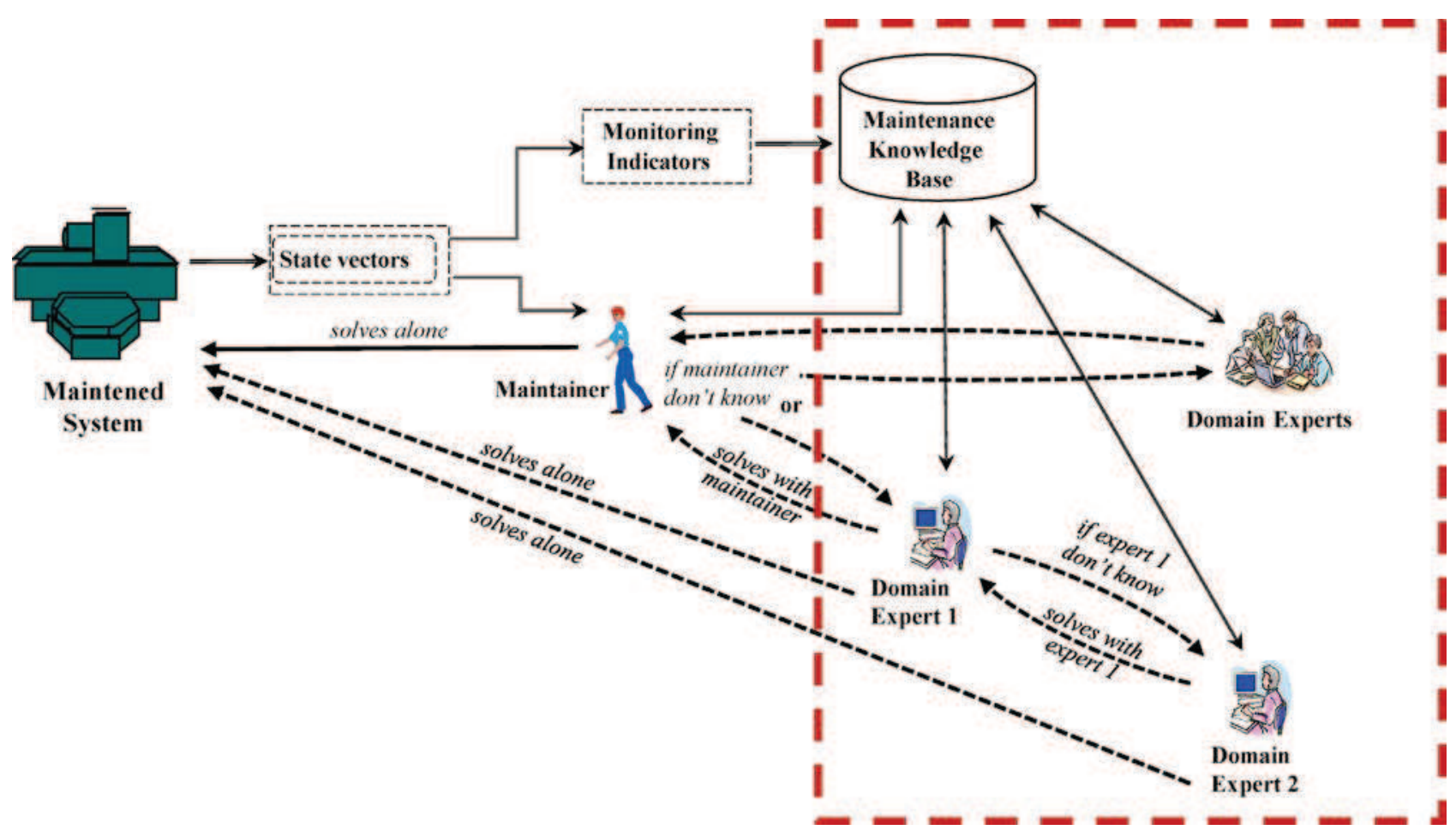

Fig. 1. Collaborative framework for multi-expert maintenance.

3.1. Proposed methodological framework for maintenance management

A collaborative approach for maintenance management will allow stakeholders to work together and lead to better decisionmaking processes in integrating knowledge of each business domain.
The approach developed below is to formalize the implementation of knowledge based industrial maintenance, using CG's mechanisms that appear suited to handle these collaborative situations. The approach involves three steps (Fig. 2):

- Cognitive modeling of experience feedback: there are different types of EF, from the use of elementary statistics (MTBF, MTTR,

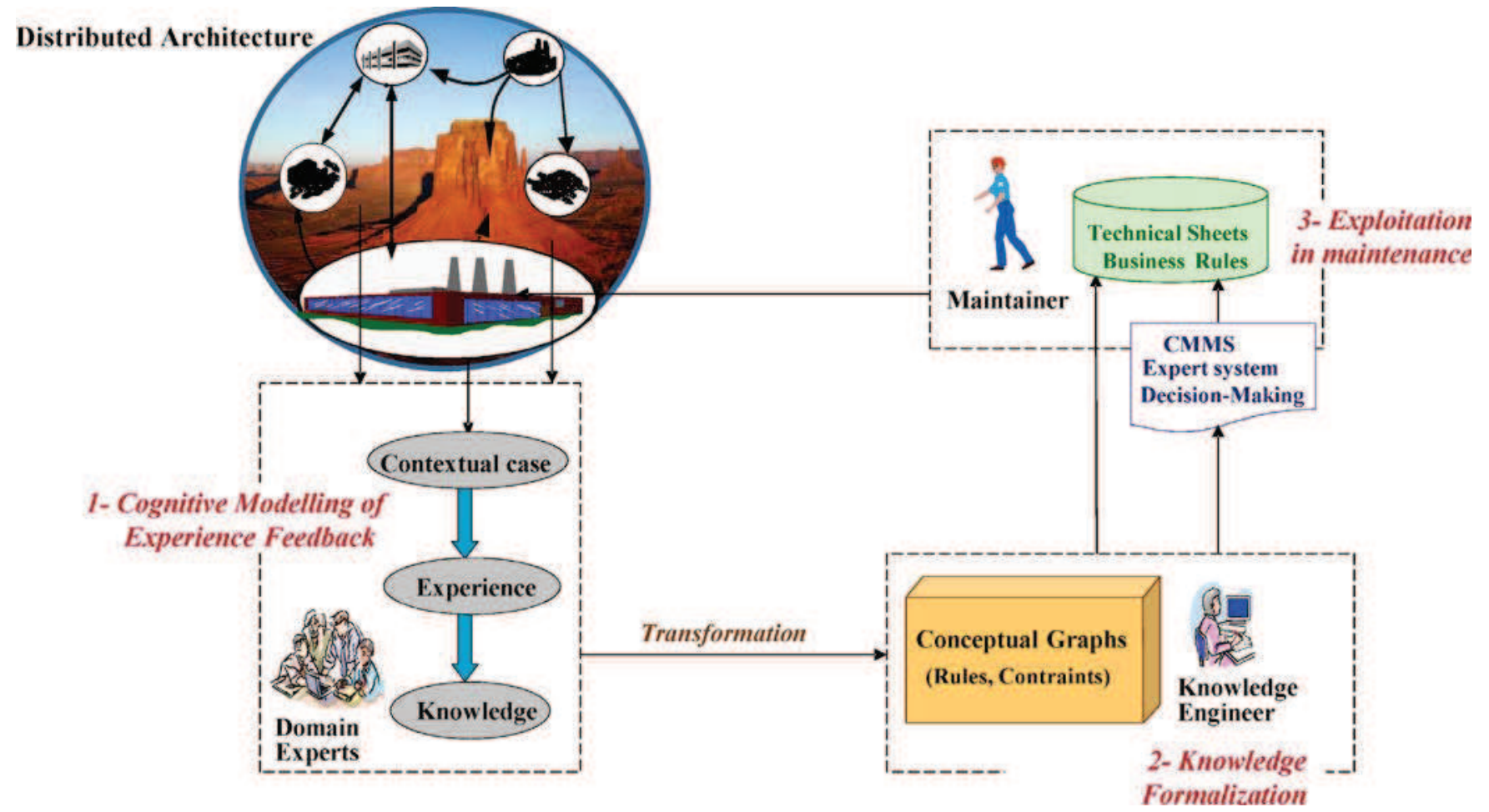

Fig. 2. Formal approach of experience feedback for maintenance management. 
etc.), to the latest methods of cognitive science based on the capitalization of experiences and knowledge [25]. In this cognitive science approach, we propose the modeling of expert knowledge of actors in order to assist the problem solving processes in a collaborative working environment. This approach is bottom-up: knowledge is gradually drawn from relevant cases initiated by triggering events (hazards, disruption, calendar data, etc.) [26]. The capitalization of cases allows for the pooling of the distributed expertise;

- Knowledge formalization: the information and communication (related theorems, indicators or assessment criteria, etc.) that ensure from the collaborating actors in the course of solving decision problem constitute knowledge. The experts' knowledge generated in step 1 is translated into a formal specification expressed in the CG formalism. This formalism provides a variety of reasoning mechanisms [27], whose use is detailed in the next section, which will allow to [28]: (i) verify the correct expression of knowledge, (ii) ensure the overall consistency of expert knowledge, (iii) detect "shortcomings" requiring additional information, (iv) assist in communication and information exchange enabling actors to work in a distributed environment.

- Exploitation in maintenance: the problem solving method of a group of actors and the resulting analysis with solution to their problem are forms of knowledge that can be capitalized [15]. The formalized knowledge is made available to the maintainer in the form of technical sheets containing structured rules, constraints and good practice guides. Their exploitation of maintenance operations will intervene in support of the maintainer in order to ensure that the equipment under his responsibility would be able to provide the required service. For instance, it will provide guidance on specific aspects of maintenance in order to help manage risk effectively.

Our work fits into the scheme of the experience feedback framework detailed in [29]. In this framework, a structured description of gradual transformation, by actors, of an event into knowledge is suggested. Using a collaborative approach, the proposed methodology seeks to promote the involvement of semantic modeling in identifying not only the defective equipment but also in determining simultaneously the significant factors that influence the success or failure of the industrial maintenance management. The case description has three components ("contextual case - experience - knowledge/lessons learned") from a cognitive experience feedback process. These components are described as follows:

- the contextual case provides a general picture of the problem to solve for enabling context reasoning and prior to in-depth analysis [30]. It contains for instance the description of faulty equipment and its use conditions when the problem occurred;

- the experience level leads to the analysis and implementation of solutions for the contextual events: search of the causes and evaluation of the effects on the system to propose corrective actions;

- the "knowledge" level summarizes the involved analysis through knowledge brought by the domain experts and generalized rules from this set of experiences (e.g. rules from accident investigations for sustainable safety improvements) [31].

Complexity considerations of today's intelligent machinery maintenance systems might lead to fault detection involving several technologies and using different diagnostic methods. These methods can be designated as follows [32]:

- electromagnetic field monitoring, search coils, coils;

- wound around motor shafts (axial flux-related detection);
- temperature measurements;

- infrared recognition;

- radio-frequency (RF) emissions monitoring;

- noise and vibration monitoring;

- chemical analysis;

- acoustic noise measurements;

- motor-current signature analysis (MCSA);

- model, artificial intelligence, and neural-network-based techniques.

During maintenance operation (e.g. diagnostic stage), it is common that the involved maintainer seeks the support of a delocalized expert. For systems whose functional requirements include several technologies (e.g. a rotary machinery system), useful knowledge is often distributed among several experts from different fields. The acquisition of knowledge from multiple experts can be a stimulating situation; then again many benefits can also be obtained (e.g. enhanced understanding of knowledge domain, improved knowledge base). Some techniques (Delphi method, nominal group technique, analytical approach, etc.) for facilitating knowledge acquisition from multiple experts are commented in [33]. We argued that the Delphi-based knowledge acquisition process [34] is a reasonable approach for conducting knowledge acquisition in collaborative maintenance problems for the two reasons: (i) it provides a mechanism for reconciliation of asynchronous conflicts between multiple experts asynchronous, and (ii) it facilitates interaction among geographically dispersed individuals in collaborative organizational systems.

We can place our approach in maintenance context with regards to fleet considerations [20]. This option can be implemented on a gradual basis since the fleet model is suitable for a distributed system with each component serving collaborative actions in the setting of industrial maintenance. Fleet composed of similar or heterogeneous components can be exploited to acquire knowledge or to find relevant information to be reused. Experts basically determine whether a situation is reusable by the general approach of analogical reasoning which provides information on some similar characteristics of the component analyzed. This improves our insight into component health and status through the analysis of events such as solicitation responses or program participation. Accordingly, the component obtains information on the health status of the other components that can help the fleet management to update on the status of real-time maintenance service and current monitoring process. So it is possible that a component highlighted the difficulties experienced in collaborating with its neighbors and we can manage to limit the severity and extent of organization disturbances and impairment to maintenance scheme functioning. Fleet has shown that one of the most reliable indicators of a component's health status is, quite simply, the collaborative assessment of their health by its neighboring components.

Likewise fleet modeling is important for the enrichment of knowledge and the advancement of better management at a global level. This fleet consideration presents a broader interpretation involving various collected cases that will contribute to expand the body of knowledge on maintenance and to further enhance adjusting monitoring of diagnosis-related activities in maintenance. Therefore, various forms of lessons learned are extensively organized to enrich the practical knowledge of maintenance, since the analysis of cases obtained seeks to develop knowledge that informs people beyond the specific situation in which the work was conducted. The fleet dimension in industrial maintenance involves generating knowledge and understanding among collaborative actors about the target system, its failure modes with prevention and management practices. 
This means that at many aspects of reliability, such considerations must be provided with the ways to check that a considered components population is in good working order; the components failures with associated root causes analysis must be made apparent to the domain actors.

In our proposition, experienced development is understood as the process of translating knowledge gained through experience feedback into news contextual situations. The specific feature of this approach resides in the engagement of graph operations to describe visual reasoning with an underpinning logical semantic model (domain ontology). In this connection, a more fleet-wide ontology approach can be used to formalize knowledge by describing the technical characteristics of the system/sub-system/equipment, the degradation modes, degradation indicators, the mission and the environments [35].

As a matter of fact, through information from a $\mathrm{CNO}$, health indicators can deepen the understanding of health monitoring issues in a components population, or current individuals' health status in a broader maintenance context. The existence of such a link of information and assessment is a way to reflect the performance of collaborative components and ensure acceptable performance levels in the operational processes. In sum, the CNO intends to serve as a channel of information for the benefit of maintenance that use their knowledge of collaborative issues to assess the status of actors involved, and to convert the information gathered into useful maintenance intelligence.

\subsection{Reasoning specification in collaborative maintenance}

If one considers that the operating state equipment is translated as a vector "signature" then its interpretation provides information on this state (or the failure factors, potential for damage, etc.). Some research describes the application of operational tools for searching and analyzing a high-volume data stream in the field of maintenance (e.g. machine monitoring, reliability analysis, fault detection and tool condition monitoring) [36]. Meanwhile, a collaborative approach in components analysis of this signature will often allow a more efficient diagnosis (speed, accuracy, precision, etc.). Indeed, through their experiences, actors involved will perceive the considered cases with alternative views and construct different knowledge from their own rules of expertise, enriching the overall diagnosis. Thus, the actors collaborate to analyze the relevant information and to identify pieces of knowledge that can be used to guide the required decision. The essential problem in the collaborative approach is to avoid contradiction and inconsistency among different domain knowledge. However, two main configurations may arise in collaborative situations: (i) compatibility of reasoning (i.e. the experts use different problem solving methods but obtain non-contradictory results) and (ii) incompatibility of reasoning (i.e. the different problem solving methods used by the experts lead to contradictory results). The formation of a single knowledge repository can integrate all expert viewpoints required for maintenance, but it is essential to study possible links between these experts' reasoning to detect conflicts or complementarities before integrating it into a collaborative decision making. In this purpose, the knowledge formalization of multiple experts in maintenance with the CG will be twofold:

- to clearly specify the expert knowledge (repairing, adjustment, servicing, monitoring and verification of equipment) that supports the positive effect of improving maintenance management in a collaborative multi-expert environment;

- to promote knowledge sharing, comparison, or even the generation of new knowledge within the knowledge repository shared by different actors involved in collaborative decision making processes associated with the maintenance of considered systems. The global aim is to achieve a better foundation for making the right decisions, and thereby reducing the amount of unplanned maintenance tasks and subsequently unplanned shutdowns.

The Multi-Agent-Systems (MAS) can offer a technical support for negotiation based on the sharing of various knowledge in remote maintenance decision-makings. For example, a ProblemOriented Multi-Agent-Based E-Service System (POMAESS) has been proposed to facilitate collaboration of maintenance processes and experts in remote service maintenance [37]. POMAESS integrates CBR-based decision support function and also uses this component to process and manage information of competing or complimentary explanations in the service maintenance problem solving. The dynamic simulation offered by the MAS for collaboration between the stakeholders makes it a valuable reference tool. However, some parameterization techniques should be extended to include the qualitative characterization of knowledge structures for the management of intangible resources or with regard to policies dealing with experience feedback processes.

Case-Based-Reasoning (CBR) is a progressive learning methodology which incorporates artificial intelligence (AI) techniques where the end-user is engaged to deal with a number of workrelated cases in order to learn how to react well to various challenging situations. Using CBR it is possible to transform the description of the maintenance process into a problem-solving model. Particularly, in the collaborative process, CBR makes it possible to take to the experienced knowledge and acts as a support system for working in concrete terms, in both a multilateral and multi-actor way.

An essential point in solving complex problems requiring the collaboration of experts is the way in which cases are organized in the case base. The distributed Case-Based Reasoning (CBR) is presented as a performance improvement solution of classical CBR systems [38]. We place ourselves in the context of a distributed CBR architecture. A distributed CBR can be used in two types of situations:

- a single agent with access to different databases in which the learned cases are distributed;

- several agents, each with its own base, collaborating to solve the problem, each agent conducts the reasoning at the local level.

Our proposal is based on the principle of "distributed" CBR architecture (Fig. 3). The goal is to reuse and combine different cases associated with reasoning from local cases to generate new solutions to complex problems addressed by a collaborative decision-making process. It would also permit a large number of actors to profit from the experience feedback and the building up of knowledge within a wide network. Several advantages arise: improvement of the knowledge and skills, greater efficiency of the reasoning process (and extension of the action spectrum) and greater effectiveness in aid delivery and improved collaboration environment, which will ultimately result in a better use of appropriate case management methods.

Collaborative CBR platform induced will have the particularity to combine different case bases $\mathrm{CB}_{i}(i=1, \ldots, n, n$ : number of experts) into a common database $\angle \mathrm{CB}>$ illustrating a series of experts, characterized by their area of competencies and combined to solve a problem (by negotiation, cooperation or collaboration) and establish a solution to this problem. Such improved CBR platform should, among other advantages, lead to the harmonization and streamlining of the respective working scenarios within the maintenance, and should enable the actors of the collaborative 


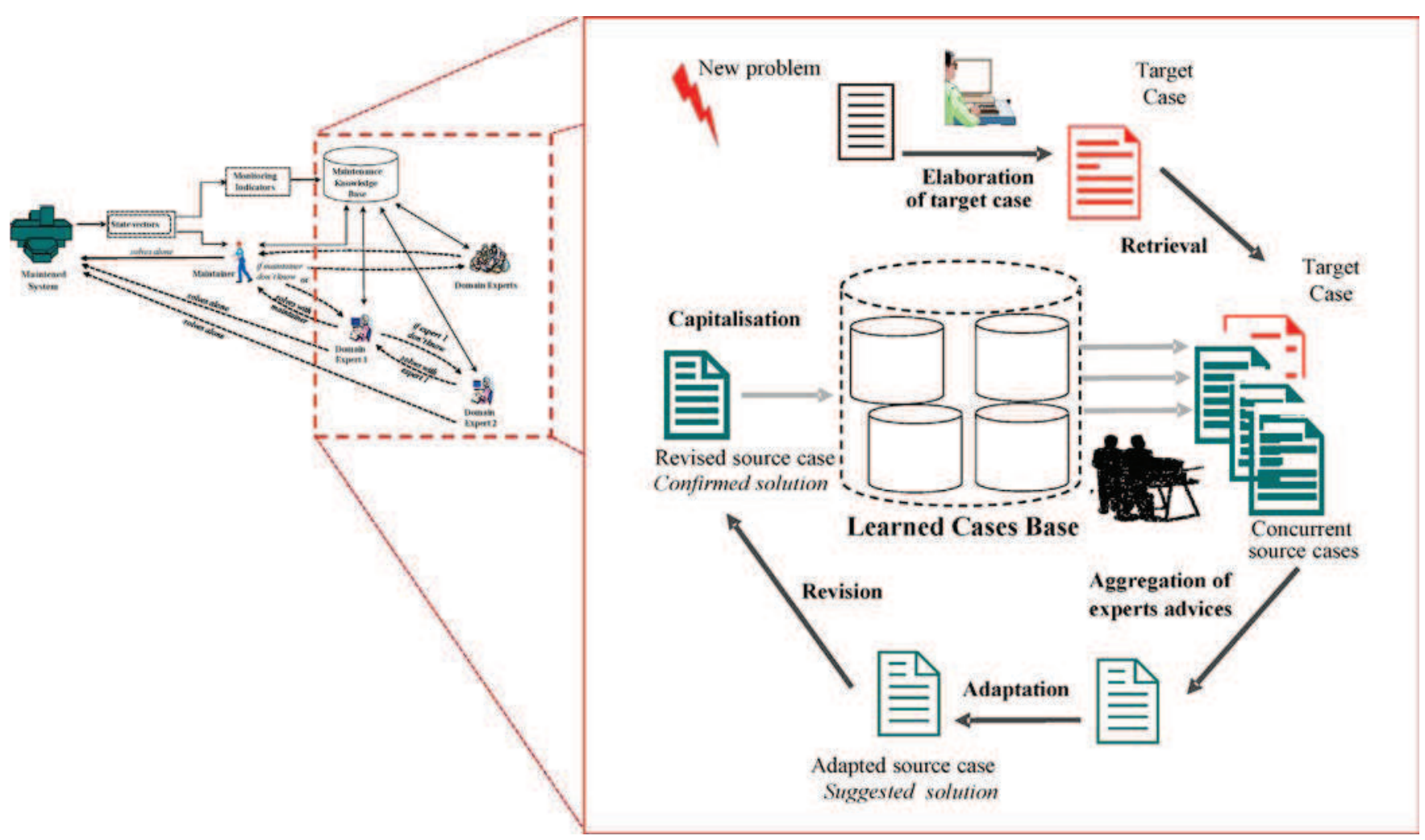

Fig. 3. Architecture of CBR integrating involvement of collaborative experts.

organization to contribute substantive inputs to the problem solving processes.

The involvement of experts can be considered between two extreme scenarios:

- partition of the problem into disjoint subsets; each expert is responsible for a part of the resolution of the problem, the solution integrates partial response;

- submission of the complete problem to each expert; the solution aggregates competing responses or is the result of a selection of these solutions.

In terms of architecture described in Fig. 3, a possible orientation combines different $\mathrm{CB}_{i}$ in a classical organization of CBR focused on the common $\angle \mathrm{CB}>$, introducing only a further step in the processing cycle: aggregation of expert advices. This step helps to develop a general solution from different points of view provided by the involved experts.

The specificity of conceptual graphs representation of human expertise will benefit from a logical background underlying the semantic modeling framework to stimulate and support collaborative actions. Furthermore, the descriptions of the reasoning become reproducible in a graph-way for better interaction between collaborative actors. The logical background ensures suitable knowledge representation and formalization for a comprehensive and coherent implementation of lessons learned from experience feedback.

\subsection{Knowledge representation formalisms}

There is a diversity of knowledge representation languages that include mainly the graph-based approach [39] (e.g. conceptual graphs and semantic networks) and the frame-based approach [40] (e.g. Frames and Descriptions Logics (DLs)):
- the frame-based approach represents knowledge using an object-like structure (e.g. individual elements and their organized classes) with attached properties. The semantics of frames are not entirely formalized, whereas the fully defined settheoretic semantics of DLs support specialized defined deductive services (e.g. knowledge consistency and information retrieval).

- the graph-based approach represents knowledge as labeled direct graphs, where nodes denote conceptual entities (concepts or relations) and arc the relationship between them. Semantics networks suffer from the lack of a clear semantics, whereas the underlying logical semantics of conceptual graphs provides a diagrammatic reasoning service allowing sentences that are equivalent to first order logic to be written in a visual or structural form.

The graph-based approach (of which conceptual graphs are a key representative) has advantages over frame-based models in expressing certain forms of modeling (e.g. mapping properties into nested contexts) and in providing a visual reasoning that facilitates an intuitive understanding. In addition, conceptual graphs can be easily translated into the terminology of some other approaches in knowledge engineering, such as Resource Description Framework Schema (RDFS) [41] and its evolution, the Web Ontology Language (OWL) [42] mainly applied in connection with the Semantic Web framework [43]. As a result, it generates the possibility to interact and exchange the modeled knowledge with internal and external collaborators.

The various forms of reasoning used in maintenance often include expert rules that must be shared by actors in a collaborative decision-making environment. These expert rules reflect the compliance with various regulations and constraints (legal requirements, organization policies, or business practices) that guide the actions of maintenance (scheduled or unscheduled). In this paper, we utilize a visual language, CG formalism for the 
specification of expert rules, which is still grounded on mathematical logic to enable formal reasoning [16]. The MULTIKAT tool [44] has experienced a method that allows the comparison and integration of coherent conceptual graphs modeling different views of expertise. The integration is based on some elementary operations (specialization, generalization and join) that support the transformation of graphs. The comparison is based on the projection operation that allows the search of semantic proximity between graph rules. These features help to manage conflicts of rules and consequences of changes, such as adding a new expert knowledge, in a knowledge base common to several experts. Ultimately, the decision maker can effectively exploit a set of knowledge rules integrating different viewpoints related to the analyzed problem and maintenance objectives set.

\section{Knowledge formalization with conceptual graphs}

The conceptual graph formalism is considered as a compromise representation between a formal language and a graphical language, because it is visual and has a range of reasoning processes [27]. Conceptual graphs can be used in many computer science areas, including text analysis, web semantics, and intelligent systems [45]. Furthermore, other notations for describing processes and events-flow-charts, state-transition diagrams, data flow diagrams, Petri nets or statecharts could be translated to nested conceptual graphs [46]. Interestingly enough, statecharts have been experimented as a mediation tool between multiple experts and a knowledge engineer, specifically when expertise is not particularly well defined [47].

\subsection{Formalism presentation}

The conceptual graph formalism is a knowledge representation language which has a well-defined syntax and a formal semantics that allows one to reason from its representations.
Definition: A simple conceptual graph is a finite, connected, directed, bipartite graph consisting of concept nodes (denoted as boxes), which are connected to conceptual relation nodes (denoted as circles). In the alternative linear notation, concept nodes are written within []-brackets while conceptual relation nodes are denoted within ()-brackets. The concepts set and the relations set are disjoint.

A concept is composed of a type and a marker $[<$ type $>$ : $<$ marker $>$ ], for example [Failure: short-circuit_09]. The type of concept represents the occurrence of object class. They are grouped in a hierarchical structure called a concepts lattice showing their inherit relationships. The marker specifies the meaning of a concept by specifying an occurrence of the type of concept.

A conceptual relation binds two or more concepts according to the following diagram:

$\left[C_{1}\right] \leftarrow$ (relation's name) $\leftarrow\left[C_{2}\right]$ (meaning that " $C_{1}$ is related to $C_{2}$ by this specific relation").

In the analysis of maintenance management, the most common relations are dependency relations, specifically, causal, conditional, temporal, and Boolean connectives, such as AND, alternating-OR and exclusive-OR relations. An example of conceptual graph is shown in Fig. 4: a service outage is caused by a service failure; an instance of criteria for determining the classes of failure severities is for availability, the outage duration. Each CG can be translated to logical formulas. The logical interpretation of a graph $G$ in Fig. 4 is defined as follows:

$\Phi(G): \exists x, y, z$ (Failure (short-circuit_09) $\wedge$ Service outage $(x) \wedge$ $\operatorname{Duration}(y) \wedge$ Availability $(\mathrm{z}) \wedge$ Agent $(\mathrm{x}$, short-circuit_09) $\wedge$ characterization $(\mathrm{x}, \mathrm{y}) \wedge$ Influence $(\mathrm{z}, \mathrm{y}))$

A derivation is a finite sequence of elementary operations on one or several nodes (concepts or relation nodes) of a CG. Examples of six elementary operations are:

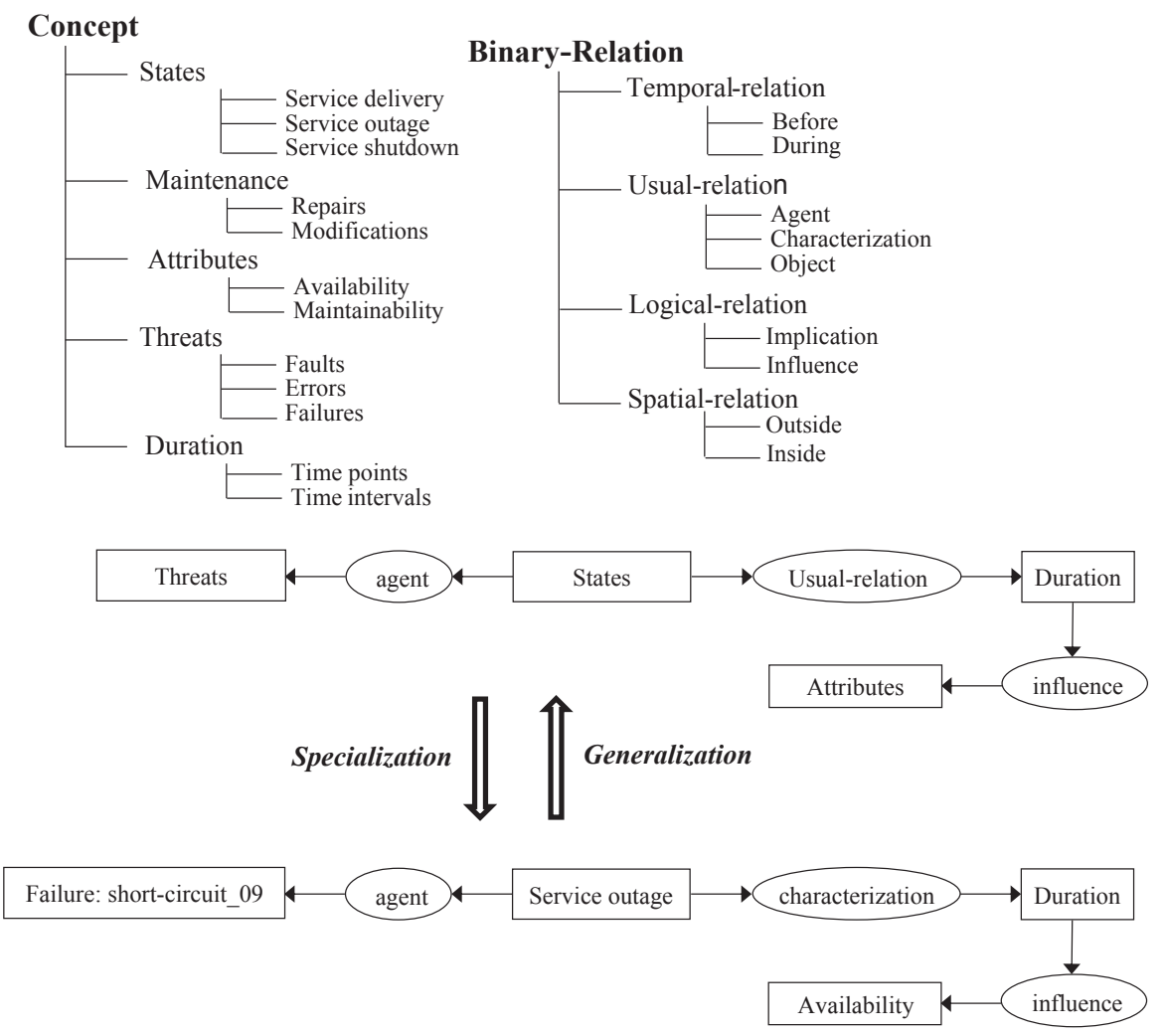

Fig. 4. Examples of concepts/relations types and conceptual graphs. 
- Simplify: this operation deletes a duplicate node and its inverse is the copy operation.

- Restrict: this operation decreases a node label (node type is replaced by one of its subtypes or the generic marker is replaced by an individual marker) and its inverse is the unrestrict operation.

- Join: this operation merges two nodes into a single super or equal node label and its inverse is the detach operation.

A derivation is a finite sequence of these elementary operations that have a formal semantics based on a logical interpretation. As a result, the meaning of graph operations is determined in light of the derivation to be applied, based on a logical interpretation which gives full effect to the visual reasoning. The derivation has one of three conceivable properties on the logical relationship between a starting graph $u$ and the resulting graph $v$ [48]:

- Equivalence: copy and simplify are equivalence rules, which generate a graph $v$ that is logically equivalent to the original: the knowledge of $u$ is included in $v$ and the knowledge of $v$ is included in $u$ (logical meaning $u \subset v$ and $v \subset u$ ).

- Specialization: join and restrict are specialization rules, which generate a graph $v$ that implies the original: $u$ contains more specific knowledge than $v$ (logical meaning $u \subset v$ ).

- Generalization: detach and unrestrict are generalization rules, which generate a graph $\mathrm{v}$ that is implied by the original: $u$ contains less precise knowledge than $v$ (logical meaning $v \subset u$ ).

Ontological knowledge provides a formal description of the maintained system (experiences and lessons learned) [49]. Expansion possibilities are preserved by the modular organization of considered concepts; we can find, for example, a maintenance division into three levels: general principles of maintenance (resource, event, etc.), in any particular domainwork, (petrochemicals, energy, transport, etc.), for a specific service. Several ontological models are available for maintenance management such as those proposed by the IEC/ISO62264, MIMOSA/CRIS and federated in the Open O \& M (Operations \& Maintenance). By providing a structured and controlled vocabulary, they assure a conceptualization relevant to the understanding and processing of maintenance problems. The ontology modeling is an iterative process with respect in accordance with four ontology design principles [50]: domain clarity, application of the identity criterion, identification of a basic taxonomic structure and explicit identification for roles. Folksonomies (collaborative tagging) suggest a collaborative informal way of online information categorisation, search and sharing [51]. They are a faceted classification scheme and provide a modeling information bottom-up that enables the emergence of semantics from a labeling of lots of things by people through shared subcommunities of interest [52].

In these communities the users have similar interests and/or domain expertise, with explicit links (through social networks their users are members of) or implicit links (through the sharing of the same tagging schemes, tags and/or objects). There are some attempts to reconcile the standardization, automated validation and interoperability of ontologies with the flexibility, collaboration and information aggregation of folksonomies [53].

\subsection{Compilation of conceptual graphs rules}

Let us consider knowledge bases (KB) composed of a set of facts (existentially closed conjunctions of atoms) and a set of rules. Let $R s$ be a set of rules in the form $H \rightarrow C$, where $H$ and $C$ are conjunctions of atoms, respectively called the hypothesis and conclusion of the rule. The conceptual graph operations allow the representation of derivation rules, and the effective application of these rules, access to a set of facts with constraints [54]. The graph rule is used in the classical way; given a simple graph, if the hypothesis of the rule projects to the graph, then the information contained in the conclusion is added to the graph.

\subsubsection{Logical semantics}

It has been shown previously that conceptual graph rules can be described by means of first-order logic augmented with the temporal operators [27]. A conceptual rule $R\left(G_{1} \Rightarrow G_{2}\right)$ is a pair of $\lambda$-abstractions $\left(\lambda x_{1}, \ldots, x_{n} G_{1}, k x_{1}, \ldots, x_{n} G_{2}\right)$, where $x_{1}, \ldots, x_{n}$, called connection points, enable one to link concept vertices of same label of $G_{1}$ and $G_{2}$. The logical interpretation of a conceptual rule $R$ $\left(G_{1} \Rightarrow G_{2}\right)$ is defined as follows: $\Phi(R)=\forall x_{1}, \ldots, \forall x_{n} \Phi\left(\lambda x_{1}, \ldots\right.$, $\left.x_{n} G_{1}\right) \Rightarrow \Phi\left(\lambda x_{1}, \ldots, x_{n} G_{2}\right)$. The semantics $\Phi$ (provided in [39]) maps each Simple Conceptual Graph $G$ into a first order logic formula $\Phi$ $(G)$. When a rule is applied in forward chaining to a conceptual graph, the information of the rule is added to the conceptual graph.

\subsubsection{Graph of rule dependencies}

A rule $R^{\prime} \in R s$ is said to depend on a rule $R \in R s$ if the application of $R$ on a fact may trigger a new application of $R^{\prime}$. Building the optimal graph of rule dependencies (notation $G R D(R s)$ ) allows one to improve the efficiency of the compilation of a rule base [55]. Concretely, in classes of rules for which forward or backward chaining mechanisms are finite, the structure of the $G R D(R s)$ provides an effective method for determining the existence of a rule deducible from the KB. In practical terms, if $R$ s admits a finitely combined partition, then it is sufficient to yield the decidability of the deduction problem [56].

Let $R s$ be a set of rules provide by domain experts, firstly we make a partition $\left(R s_{1}, \ldots, R s_{n}\right)$ between rules according to expert groups of compatible viewpoints. Secondly, within each $R s_{i}$, we make a finitely combined partition based on the notion of dependencies between rules that obey some constraint preserving decidability. Such partitions are interesting as they permit to reason sequentially and independently with the two levels of sets of rules.

\subsubsection{Exploitation of conceptual graphs for multi-expertise in maintenance management}

A formal knowledge modeled by CGs in experience feedback processes can be a very useful tool for conveying an accurate meaning to a collaborative work environment between domain experts [57]. For a given application, several viewpoints of expertise may be engaged in combination. For example, some investigations to improve the availability of a rotary machinery system can involve expert knowledge in mechanics, electricity, cybernetics and remote access computing. It will be constructed for each knowledge expert rule associated to a specific domain, a conceptual graph rule. In the maintenance management context, each rule has a symbolic form $H \rightarrow C$, where $H$ is a CG context's hypothesis part and $C$ is a part CG analysis' conclusion. For binary relations, the basic relationship is as follows: $C_{\text {in }} \rightarrow($ rel $) \rightarrow C_{\text {out }}$ also marked by $C_{\text {in }}{ }^{1} \rightarrow(\text { rel })^{2} \rightarrow C_{\text {out }}$.

During the knowledge modeling phase of the maintenance rules, the use of CG properties will help to enrich the maintenance knowledge base in order to ease their access, sharing and reuse by the members of the industrial maintenance management in their individual and collective tasks [58]. The base of canonical CGs to a maintenance problem can be partitioned according to viewpoints corresponding to schools of thought. For the fusion of expert rules, the general idea is to apply a conjunctive procedure within groups of compatible viewpoints, and a disjunctive procedure across groups of complementary viewpoints [59]. These procedures for comparing two graph rules are based on criteria of generalization 
versus specialization, and conceptualization versus instantiation. In the following, we will explain the construction of integrated graphs rules according to the chosen procedure:

- Conjunctive procedure: the preconditions are that experts share an explanation of the maintenance problems since they are all reliable but not independent information sources. The conjunctive procedure relies on the intersecting knowledge of different experts. The specialization operation is used when an expert is more specialized than the others on a given aspect, and uses more precise expressions. The conceptualization is used when an expert focuses on particular cases and on specific examples, while the other expert expresses general knowledge at a better level of abstraction. This conjunctive procedure deals with contradiction as far as the degree of conflict remains low between experts within groups having compatible reasoning. The conjunction procedure produces a trivial result when the information sources conflict completely. In this case, the fusion falls into pure contradiction with incompatible reasoning.

- Disjunctive procedure: the preconditions are that at least one expert's theory, but not all theories, is a reliable information source. The experts' rules describe independent and complementary viewpoints. In such case, it is impossible to make a selection between both expert rules. The disjunctive procedure relies on the connection of the graph rules by their common concepts in the maintained equipment with maximal joint operation.

This highlights the interest of studying interactions between rules in order to better characterize their dependencies and the analysis of combined information. We therefore have the opportunity to apply graphs operations not only for curative purposes in the maintenance, but also for preventive goals in order to avoid similar difficult situations (failure or damage) in future. Experience gained and lessons learned from initial problem solving developments will be applied as soon as possible in similar situations in other collaborative maintenances.

\section{Application example: a rotary machinery system}

We illustrate the proposed approach using CGs with the case study of a rotary machinery system (Fig. 5). One difficulty in such a system is the heterogeneity of the failure laws of mechanical and electrical components which are, furthermore, integrated into modules equipped with sensors and actuators. Each system's component is subject to an individual pattern of malfunction and replacement, and all parts together make up the failure pattern of the equipment as a whole.

The rotary machinery system that we consider here is taken from [60] in which the authors were interested in the reliability in order to detect earlier any imminent failures and reduce risks. The mainstream of the involved maintenance applications focuses more on common rotary machinery components, such as bearings, gears and motors. Table 1 illustrates possible failure modes of

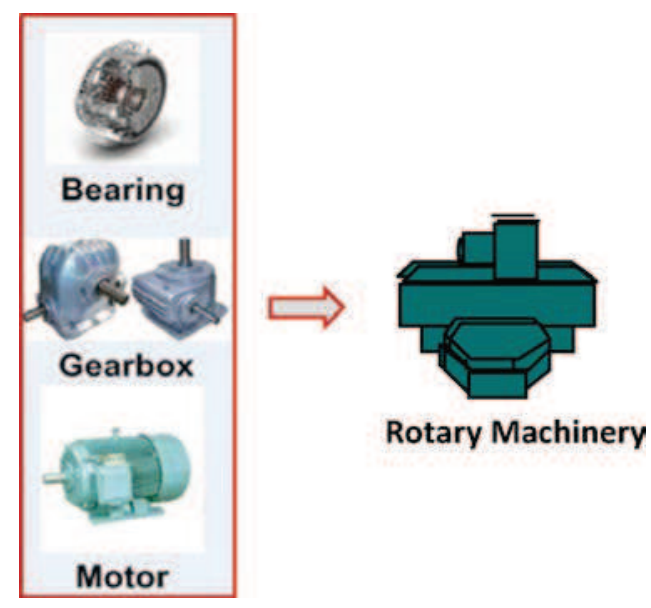

Fig. 5. The rotary machinery system.

these critical components, with their characteristics and common detection techniques. The main groups of detection techniques are mechanical, like vibrations and acoustic, and electrical, like currents and voltages. Others different techniques, such as acoustic measurements or chemical analysis are also engaged to investigate the nature and the degree of the fault. It is also important to identify the most frequent failure initiators, failure contributors and underlying causes [61].

\subsection{System modeling with CGs}

The maintenance tasks can be initially evaluated by different specialists of the involved fields. As the lessons are learned, a knowledge-base can be generated and used to guide possible maintenance actions and operating scenarios. We present in Fig. 6 a sample of the expert rules relative to the failure processes of a rotary machinery system. Specialists are grouped according to the theoretical or experimental connections of their scientific disciplines: for instance we put together mechanical and thermodynamics specialists in one group, while materials and chemicals specialists in another group. In association with electrical specialists, the first group concentrates on the failure initiators, whereas the second group pays more attention on the failure contributors. Comprehensive underlying causes are identified collaboratively by all the specialists of the involved fields of science and technology. Expert rules are linked with the maintenance of common critical components. Here, a finitely combined partition of the used set of rules is $\left\{\left\{R_{1}, R_{2}, R_{3}\right\},\left\{R_{4}, R_{5}\right\},\left\{R_{6}, R_{7}, R_{8}\right\}\right\}$. The eight expert rules are expressed separately in distinct conceptual graphs.

A failure initiator is the event or mechanism that initiates a process which could potentially lead to failure or damage in a studied system. Without either the latent condition for failure or the failure initiator, the system will continue to run reliably. Many mechanisms might trigger the onset or exacerbation of error or the

Table 1

Characterization of failure modes of common rotary machinery components.

\begin{tabular}{|c|c|c|c|}
\hline Component & Failure & Characteristic & Common measures \\
\hline Bearing & $\begin{array}{l}\text { Rolling-elements and cage failures, abrasion, fatigue and } \\
\text { pressure-induced welding }\end{array}$ & $\begin{array}{l}\text { Raw data does not contain insightful information, low } \\
\text { amplitude, high noise }\end{array}$ & $\begin{array}{l}\text { Vibration, oil debris, } \\
\text { acoustic emission }\end{array}$ \\
\hline Gear & $\begin{array}{l}\text { Manufacturing error, tooth missing, tooth pitting/spall, } \\
\text { gear crack, gear fatigue/wear }\end{array}$ & $\begin{array}{l}\text { High noise, high dynamic, signal modulated with other } \\
\text { factors (bearing, shaft, transmission path effect), gear } \\
\text { specs need to be known }\end{array}$ & $\begin{array}{l}\text { Vibration, oil debris, } \\
\text { acoustic emission }\end{array}$ \\
\hline Motor & Stator faults, rotor electrical faults, rotor mechanical faults & $\begin{array}{l}\text { Currents and voltages are preferred for non-invasive } \\
\text { and economical testing }\end{array}$ & $\begin{array}{l}\text { Stator currents and } \\
\text { voltages, magnetic } \\
\text { fields and frame } \\
\text { vibrations }\end{array}$ \\
\hline
\end{tabular}




\begin{tabular}{|l|l|l|}
\hline Context: rotary machinery failure \\
\hline description \\
\hline Faults & & \\
\hline
\end{tabular}

\begin{tabular}{|c|c|c|c|}
\hline \multirow{3}{*}{2 implication } & \multicolumn{3}{|c|}{ Analysis: failure initiator } \\
\hline & description & & \\
\hline & Detection & 1 attribute 2 & Mechanical breakage \\
\hline
\end{tabular}

\section{Rule 1-Mechanical specialist}
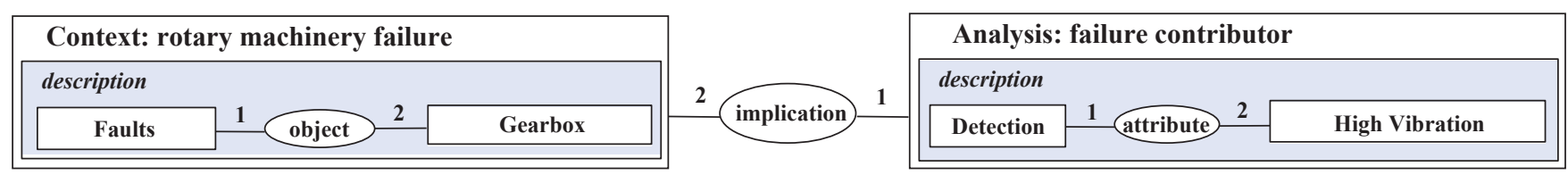

\section{Rule 2-Mechanical specialist}
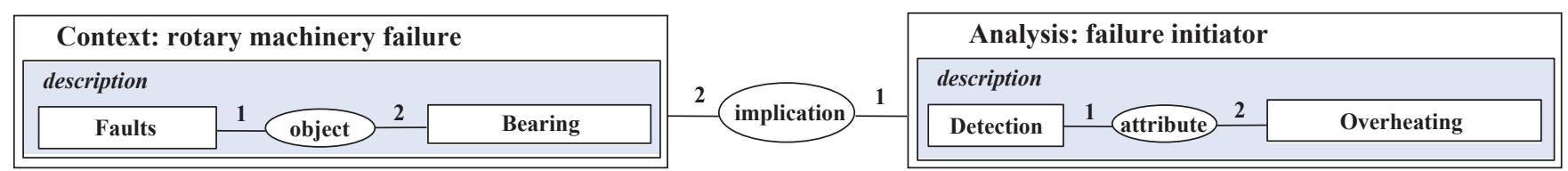

Rule 3- Thermodynamics specialist

\begin{tabular}{|c|c|c|}
\hline \multicolumn{3}{|c|}{ Context: rotary machinery failure } \\
\hline description & & \\
\hline Faults & object & Motor \\
\hline
\end{tabular}

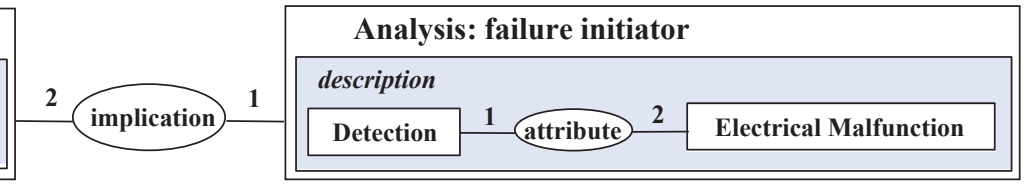

Rule 4- Electrical specialist

\begin{tabular}{|l|l|l|}
\hline \multicolumn{2}{|c|}{ Context: rotary machinery failure } \\
\hline description & & \\
\hline Faults & & \\
\hline
\end{tabular}

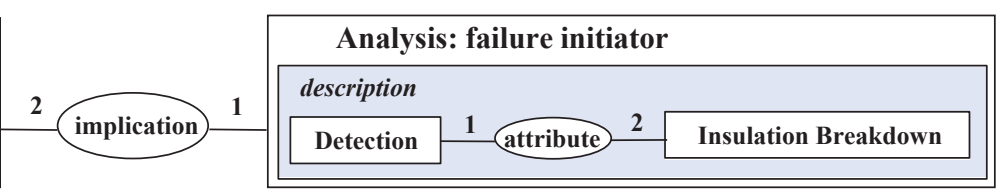

Rule 5- Electrical specialist
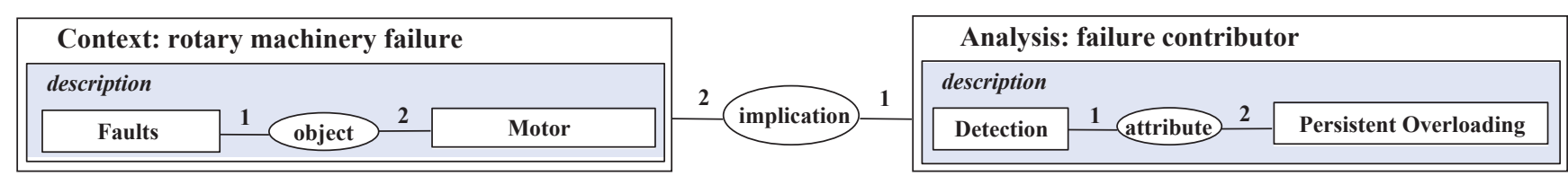

\section{Rule 6 - Materials specialist}

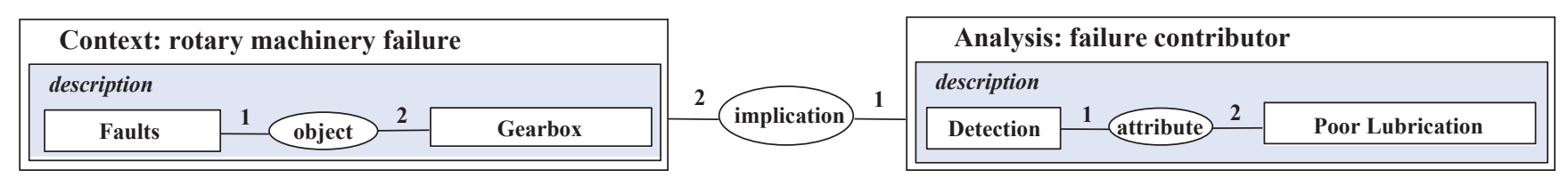

Rule 7 - Chemical specialist

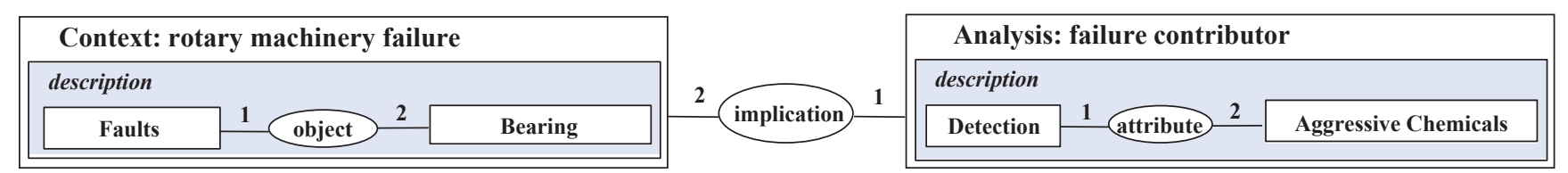

Rule 8 - Chemical specialist

Fig. 6. Eight conceptual graph rules formalizing experts' knowledge. 
development of failure. The problem solving in maintenance is a decisive issue, requiring both a deep examination of the underlying causes and careful consideration of the most effective methods for achieving a significant and sustained reduction in failure initiators and contributors. It is known that a maintenance problem is always activated by some failure initiators and can be exacerbated by potential failure contributors. The failure initiator might be different from the failure contributor that ultimately leads to the damage propagation and the system failure. Often, what appears to be the problem is only its visible part (symptom and effect of underlying causes) that may not also be representative of the total content of problem. The failure initiator is mainly triggered by a design problem that remained inherent for a considered system. The failure contributor is often generated by a driving practice that stays inappropriate for a target system. The statistical analysis can explain the major factors of a failure situation and may be used to better understanding the historical description of problems in maintenance for the studied system. The descriptive statistical analysis of industrial raw data provides interesting information and permits refined the roles of multiple involved variables with the determination of most influential in order to prevent a resurgence of damage and failure. Maintenance could benefit from collaborative workshops and resource materials that provide insight into the underlying causes and operational means to discover effective ways to prevent them from happening in the future. When a strong correlation between underlying causes, failure initiators, failure contributors and failure modes has been established by controlled studies, a rule can be devised that relates some consequence adjustment factors with expert opinions. Rather than the classical elucidation of approaching the failure problem as a collection of independent factors that are eventually linked together, a unified methodology opens new possibilities by treating the system failure process with a comprehensive view.

In the context of possible failure modes on rotary machinery system, the main failure initiators are electrical faults or malfunctions, mechanical breakage, overheating, and other insulation breakdowns. The collected experiences indicate that the failure contributors' high vibration, persistent overloading and aggressive chemicals are the most important. The lessons learned show that the most frequent underlying causes are defective components, improper operation, and inadequate physical protection. The arguments of the expert knowledge rules become associated with the focus on formal troubleshooting procedures; preventive maintenance and safety issues revolving around components within the rotary machinery system. In the eight rules, the different specialists apply troubleshooting strategies to identify, localize and (where possible) correct malfunctions.

\subsection{Visual reasoning of maintenance analysis procedures}

The development of such conceptual rule models is to the advantage of conversion of tacit into explicit knowledge. This transformation expands the knowledge acquired or discovered by individuals and its formal representation aims at providing shared meanings of maintenance analysis procedures. Shared interpretations are valuable to improve communication between experts for strengthening their collective knowledge. After knowledge is acquired and formalized, it is concretely exploited by means of knowledge management methods and tools [26]. For instance, in an analogous way to the query-based cross-language diagnosis tool presented in [62], it is possible to build a query CG basedlanguage diagnosis tool for assisting users diagnosing equipment defect troubleshooting. The conceptual framework is wellequipped to handle the situation of how users troubleshoot problems by query diagnoses, with an existing ontology-based semantic search engine that implements such a matching function using the CG reasoning operations (validation and inference services) [63].

It is important for the maintenance system to have comprehensive information and knowledge formalization on which to base the collaboration policy decisions and responses to complex problem situations. The pragmatic strategy is intended to develop sufficient awareness and capacity among collaborative actors, communities and organizations so that they can prevent or remediate existing problems.

The conventional techniques (e.g. traditional CBR) cannot be used to support the problem. In that connection, we would like to stress two significant points.

- It was important to gain a clear idea of how knowledge representation in that $\langle\mathrm{CB}>$ would proceed.

Each expert has its own mode of reasoning according to his experiences and domain of competence.

This is a clear demonstration of the need to rely on domain ontology and a dedicated language such as conceptual graphs, since if everyone adopts the appropriate level of formalization for cases description; it is possible to achieve formal knowledge representation.

- The case base $<\mathrm{CB}>$ will be progressively and regularly updated on the basis of new lessons learned in the treatment of new cases. The application of rigorous control and monitoring procedures would provide a clear and constantly updated view of $\langle\mathrm{CB}\rangle$, particularly with regard to the underlying policy objectives and industrial evolution.

Our conceptual graph modeling approach can be regarded as complementary to the conventional techniques development (e.g. CBR), because graph-based communication should be an element that reinforces the efficiency of knowledge representation by making it comprehensible and facilitating its semantic sharing by collaborative actors. The reasoning operations (derivation, specialization, generalization and projection) of CGs strengthen collaboration by emphasizing the primacy of knowledge that is validly enacted by the collaborative actions of experts.

On the one hand, we consider now the integrative join of the eight expert rules in a single graph describing the collaborative expertise (as shown in Fig. 7).

This join has to first find the concepts belonging to the minimum common generalization of involved graphs and then only keep those from their common maximum specialization. In particular, inspection of the graphs shows, for example, the possibility of generalization between the concepts Bearing, Gearbox and Motor that are all the equipment component of the rotary machinery system. Similarly, the concepts electrical malfunction, mechanical breakage, overheating, and insulation breakdown are all types of failure initiators. We then explained that the concepts with similar role (failure initiators, failure contributors and underlying causes) in the analysis of system reliability are merged into one single CG.

On the other hand, we can use this experienced knowledge for dedicated analysis of the studied system. For example, we seek out specific problems on Motor which would justify sectorial targeting of actions. In such a situation, the projection operation provides that the three alternative pieces of experienced knowledge (rules 4,5 and 6) can be selected to establish that the priorities and measures that are directed at resolving the major problem of the Motor (Fig. 8). Moreover, there is a need for joint efforts on everyone's part to overcome deplorable state of component equipment failures and to translate proactive gained knowledge into action. Expert teams should discuss what they would do in this 


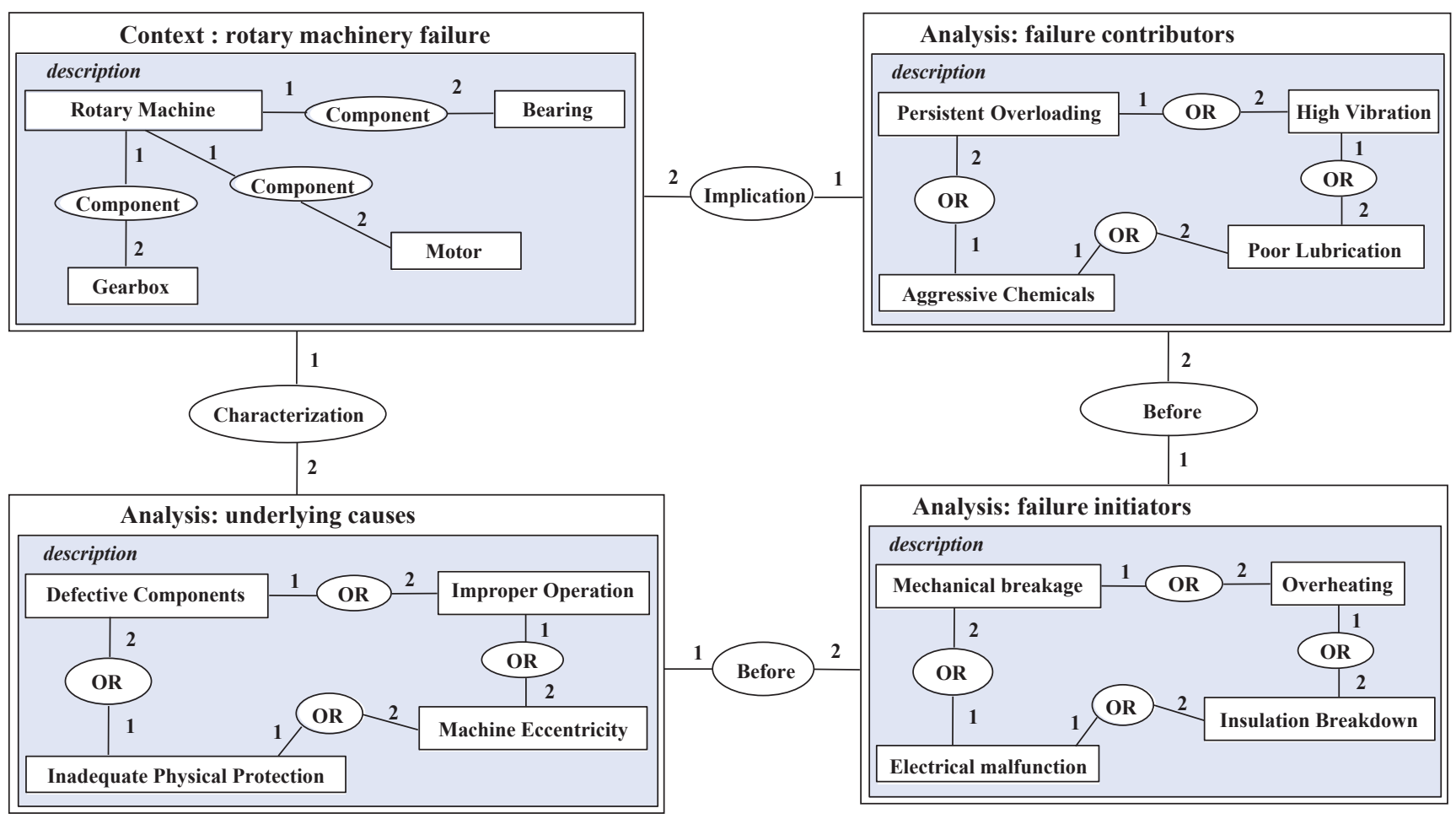

Fig. 7. A conceptual graph rule formalizing the collaborative integration of expert rules.

kind of problem solving, and settle appropriate plans, so that maintainers are supported in any reliability action they take with CGs reasoning and their visual operations. These operations took account of a preliminary study incorporating a statistical analysis by maintenance center, an analysis of advanced knowledge and continuous technological intelligence. Using statistical analysis and visualization tools on maintenance data is now an integral part of any technological intelligence activity in experience feedback processes.

Thus in order to assess, interpret and validate the reasonableness of the modeled rules, one would have to ensure that the various types of situations targeted by using the projection operation of CGs. We are interested in CGs to leverage their specific visual capabilities of expressive representation and communicative reasoning which allow the user to properly evaluate the rules as to identify those he considers being the most interesting within a broad analytical framework. In the same vein, we can distinguished two generic types of rules model that can be considered by the user to specify his contextualized requirements by explicitly describing the rules separately labeled as interesting and non-interesting ("include template" and "exclude template") [64]. Thus, each modeled rule is compared with the elements of the sets of two types of predefined generic models. A rule is said to be considered satisfactory if it is a specialization of at least one rule considered interesting ("include template") and if it does not match any specialization of rules considered non-interesting ("exclude template"). Such a classification is always improving the analysis of modeled rules by more effective interaction to facilitate an agreed interpretation of the results [65]. The rule selection mode can be easily transposed to the reasoning system of

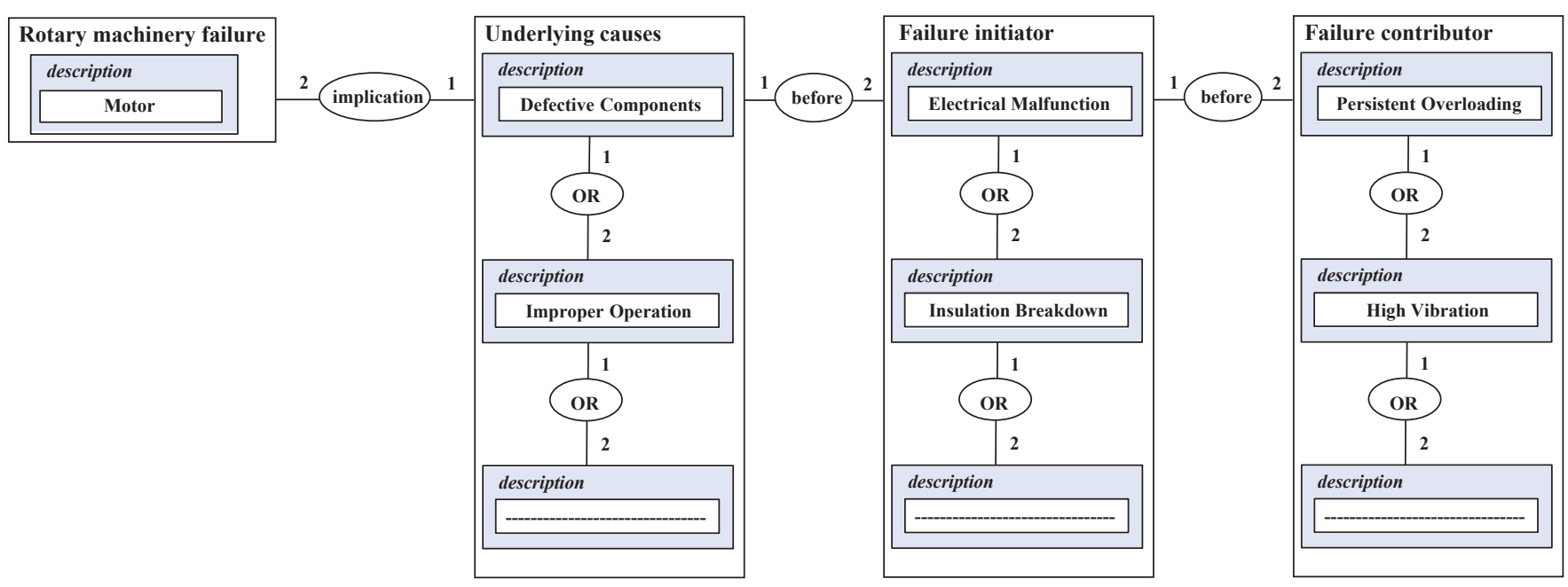

Fig. 8. A conceptual graph rule formalizing motor failure. 
conceptual graphs in which the projection operation can be used to pass judgment on the validity of other graphs [54]. This operation and its derivations are used to perform the rule selection verifying the specified requirements by checking the validity of their graph with respect to a rule base asserted by graphs. In the above example, it was possible to find a reasonable matching between specified CG rules and target monitored maintenance transactions. Thus, the rules selection would have to proceed to informed choices of the preventive or curative actions to be chosen for maintenance. Hence, we could measure directly the effect of the graphical reasoning on actors' ability to obtain appropriate knowledge in line with actions identified in the collaborative strategy concerning maintenance management. Furthermore, the problem should not be viewed as the problem of one expertise more than another but as a global problem which all involved members of the collaborative organization would address.

\subsection{Discussion}

It is also important to combine the symbolic and numerical reasoning in complementary ways. In order to organize numerical reasoning, the industrial maintenance framework draws its knowledge from the wealth of information available from experts, customers, practical research and published documentation on system performance and failure modes. They concern in particular the various dates related to products (commissioning, all failures with the places at which such failures were made and recommissioning). The maintenance journal records furnish details for the extent of the work performed and the components exchanged and installed. The analysis requires the description of significant assumptions with root causes investigation and the potential use of external expertise. A lowering of corrective maintenance, and therefore an improvement in industrial performance, is achieved through experience feedback- and reliability-oriented maintenance; unplanned downtimes are reduced. Some guidelines can be used for planning a reliability growth test with an applicable model (e.g. Duane model) and the contribution of expertise enabling us to identify failure modes, and validate facts that help us direct the focus of the investigation. The objective is to find failures during test and learn from those failures by improving the conditions for the functioning of studied systems or redesigning to eliminate them. Another analysis can be conducted to identify and describe potential failure modes for assessment and inclusion in a surveillance program. The analysis and interpretation of the results are frequently determined using the Weibull method. Further actions can be made to define the key parameters of surveillance to support the maintenance operations, building on the identified modes of failure. To avoid any rupture in its logistical chain which may lead to a stoppage of the services and resources availability, it is up to the maintenance management to assess the appropriateness of the constitution by it of a pertinent safety stock. This requires an in-depth investigations and a detailed risk assessment to identify the manner by which a system may fail to operate correctly, predict the potential consequences of such a failure, and establish specific engineering measures (e.g. using a Poisson distribution) to mitigate the consequences to tolerable levels [66]. Establishing a baseline of experienced knowledge at a maintenance level is essential in order to implement the collaboration, as appropriate, in exchanging timely and accurate information concerning the problem solving and its prevention. Maintenance management services benefit from more efficient, timely, and accurate collection, interpretation, and analysis of information with corresponding benefits of a shortened investigation process and more timely communication of reliability deficiencies and problem solving reports to stakeholders and the logistics.
Our work has some common features with the Decisional DNA's approach $[67,68]$ : (i) the Set of Experience Knowledge Structure, used to model the user's experience and (ii) the exploitation of embedded knowledge in the domain of industrial maintenance. However, this approach has a restriction: some physical models (functions) are needed to describe knowledge experience of a specific domain.

\section{Conclusion and related works}

In this paper, we have shown that the use of cognitive experience feedback and formal semantic techniques provide additional support to maintenance tasks by improving the user understanding of the components being maintained. The creation and exploitation of collaborative knowledge of experts in the course of handling maintenance problem resolution yield relevant knowledge which is accessible to them based on their needs. Relying on the modeling of expert knowledge through conceptual graphs operations, we proposed an approach that positively impacts the maintenance management plans:

- a better access to the lessons acquired from the experience feedback process through intelligent information retrieval based on a formalized domain vocabulary;

- a framework for experts knowledge sharing that promotes the crossing of points of views. They provide additional support to tolerate or prevent failures and optimize equipment availability [69];

- a possible conceptual model of a maintenance management system that combines knowledge, user experience and semantic techniques.

The outlook in the short term of this work is:

- a description of meta-rules for the study of the consistency of a set of expert rules;

- the research of conflict resolution techniques (negotiation logic or determining priorities for interpretation);

- the consideration of changing the risk management mechanisms and decision-making in conflict situations.

For the medium term, we wish to introduce a major idea: the description of a way of capitalization of the trace of reasoning after a collaborative problem solving. Amongst the actions which can be applied, a range of semantic procedures can help to monitor collaborative operations and track problem solving from point of initiation, through processing negotiations, changes and on to final resolution.

The expected added value is the proposal of experience feedback system on management of collaborative decision schemes achieving a knowledge capitalization method that allows understanding the way in which collaborative reasoning is efficiently conducted through appropriate choices [70]. In particular, the instrument of the collaborative CBR, with its distributed and teamwork mechanisms, can be managed to ensure that the problem solving process is well directed and is determined in good time.

Moreover, the possible benefit is to future complex situations with the collective knowledge through a gathering of collaborative practices. This requires developing methods and techniques to promote suitable knowledge tracking systems; the key point is to build up a sustainable and semantically formal reasoning framework that allows tracking of actions taken and decisions made [71].

Similarly, this work should be concerned with two forms of long-term extension: 
- to benefit from the matching of CG with semantic web languages to position the approach in the context of e-maintenance;

- to study the relationship with the theory of belief functions which offers potential applications [72] for cases where the combination of heterogeneous information plays an important role.

\section{References}

[1] E. Zio, Reliability engineering: old problems and new challenges, Reliability Engineering \& System Safety 94 (2) (2009) 125-141.

[2] G. Fernández, J. Francisco, A.C. Márquez, Framework for implementation of maintenance management in distribution network service providers, Reliability Engineering \& System Safety (2009), http://dx.doi.org/10.1016/j.ress. 2009.04.003.

[3] L.M. Camarinha-Matos, D. Afsarmanesh, N. Galeano, A. Molina, Collaborative networked organizations - concepts and practice in manufacturing enterprises, Computers \& Industrial Engineering 57 (2009) 46-60.

[4] C. Frank, M. Gardoni, Information content management with shared ontologies at corporate research centre of EADS, International Journal of Information Management 25 (1) (2005) 55-70.

[5] P. Panzarasa1, N.R. Jennings, T.J. Norman, Formalizing collaborative decisionmaking and practical reasoning in multi-agent systems, Journal of Logic and Computation 12 (1) (2002) 55-117. , http://dx.doi.org/10.1093/logcom/ 12.1.55.

[6] J.L. Soubie, P. Zaraté, Distributed Decision Making: A Proposal of Support Through Cooperative Systems. Group Decision and Negotiation, vol. 14(2), Springer Verlag, 2005, pp. 147-158 http://www.springeronline.com.

[7] A. Seguy, D. Noyes, P. Clermont, Characterisation of collaborative decision making processes, International Journal of Computer Integrated Manufacturing 23 (11) (2010) 1046-1058

[8] C. Kolski, P. Millot, Problems in telemaintenance and decision aid criteria for telemaintenance system design, International Journal of Industrial Ergonomics 11 (2) (1993) 99-106.

[9] B. Iung, E. Levrat, A. Crespo Marquez, H. Erbe, Conceptual framework for emaintenance: illustration by e-maintenance technologies and platforms, Annual Reviews in Control 33 (2) (2009) 220-229.

[10] R. Gouriveau, D. Noyes, Risk management - dependability tools and case-based reasoning integration using the object formalism, Computers in Industry 55 (3) (2004) 255-267.

[11] J.A. Harding, M. Shahbaz, Srnivas, A. Kusiak, Data mining in manufacturing: a review, Journal of Manufacturing Science and Engineering 128 (2006) 969-976.

[12] B. Kamsu Foguem, F. Rigal, F. Mauget, Mining association rules for the quality improvement of the production process, Expert Systems With Applications 40 (4) (2013) 1034-1045

[13] R.O. Weber, D.W. Aha, Intelligent delivery of military lessons learned, Decision Support Systems 34 (3) (2003) 287-304.

[14] H. Jabrouni, B. Kamsu-Foguem, L. Geneste, C. Vaysse, Continuous improvement through knowledge-guided analysis in experience feedback, Engineering Applications of Artificial Intelligence 24 (8) (2011) 1419-1431.

[15] B.F. Oladejo, V.T. Odumuyiwa, A.A. David, Dynamic capitalization and visualization strategy in collaborative knowledge management system for El process, World Academy of Science, Engineering and Technology (66) (2010) $525-533$.

[16] J.F. Sowa, Knowledge Representation: Logical, Philosophical, and Computational Foundations, Brooks Cole Publishing Co., Pacific Grove, CA, USA, 2000p. 608ISBN: 0-534-94965-7.

[17] B. Kamsu-Foguem, V. Chapurlat, Requirements modelling and formal analysis using graph operations, International Journal of Production Research 44 (17) (2006) 3451-3470

[18] P. Smets, Decision making in the TBM: the necessity of the pignistic transformation, International Journal of Approximate Reasoning 38 (2) (2005) 133-147.

[19] D. Paris, L.C. Trevino, M.D. Watson, IVHM Framework for Intelligent Integration for Vehicle Health Management, 2005 NASA Technical Documents, Identifier: nasa_techdoc_20050092389, Document-source: CASI.

[20] D. Vujanović, V. Momčilović, N. Bojović, V. Papić, Evaluation of vehicle fleet maintenance management indicators by application of DEMATEL and ANP, Expert Systems with Applications 39 (12) (2012) 10552-10563.

[21] M. Esperon-Miguez, P. John, I.K. Jennions, A review of integrated vehicle health management tools for legacy platforms: challenges and opportunities, Progress in Aerospace Sciences 56 (2013) 19-34.

[22] A. Crespo-Marquez, B. Iung, A review of e-maintenance capabilities and challenges, Journal on Systemics, Cybernetics and Informatics 6 (1) (2008) 62-66.

[23] A. Muller, A. Crespo Marquez, B. Iung, On the concept of e-maintenance: review and current research, Reliability Engineering \& System Safety 93 (8) (2008) 1165-1187.

[24] I. Lopez, N. Sarigul-Klijn, A review of uncertainty in flight vehicle structura damage monitoring, diagnosis and control: challenges and opportunities, Progress in Aerospace Sciences 46 (7) (2010) 247-273.

[25] I. Rasovska, B. Chebel-Morello, N. Zerhouni, A mix method of knowledge capitalization in maintenance, Journal of Intelligent Manufacturing 19 (3) (2008 347-359.
[26] R. Bergmann, Experience Management: Foundations, Development Methodology, and Internet-Based Applications, vol. 2432 of Lecture Notes in Artificial Intelligence, Springer, 2002.

[27] M. Chein, M.-L. Mugnier, Graph-based Knowledge Representation: Computational Foundations of Conceptual Graphs. Series: Advanced Information and Knowledge Processing, Springer, London, UK, 2008, p. 445ISBN: 978-1-84800-285-2.

[28] B. Kamsu-Foguem, G. Diallo, C. Foguem, Conceptual graph-based knowledge representation for supporting reasoning in African traditional medicine, Engineering Applications of Artificial Intelligence 26 (4) (2013) 1348-1365.

[29] H. Rakoto, P. Clermont, L. Geneste, Elaboration and exploitation of lessons learned, Intelligent Information Processing (2002) 297-300 (in press).

[30] R. Gong, K. Ning, Q. Li, D. O'Sullivan, Y. Chen, S. Decker, Context modeling and measuring for proactive resource recommendation in business collaboration, Computers \& Industrial Engineering 57 (1) (2009) 27-36.

[31] J. Lund, L.E. Aarø, Accident prevention, presentation of a model placing emphasis on human, structural and cultural factors, Safety Science 42 (4) (2004) 271-324.

[32] S. Nandi, H.A. Toliyat, X. Li, Condition monitoring and fault diagnosis of electrical motors - a review, IEEE Transactions on Energy Conversion 20 (4) (2005) 719-729.

33] L. Medsker, M. Tan, E. Turban, Knowledge acquisition from multiple experts problems and issues, Expert Systems with Applications 9 (1) (1995) 35-40.

[34] H.A. Linstone, M. Turoff, Delphi: a brief look backward and forward, Technological Forecasting and Social Change (2010) (in press).

[35] G. Medina-Oliva, A. Voisin, M. Monnin, F. Peysson, J.-B. Leger, Prognostics assessment using fleet-wide ontology, in: Annual Conference of the Prognostics and Health Management Society 2012, PHM Conference 2012, September, Minneapolis, MN, USA, 2012

[36] A. Alzghoul, M. Löfstrand, Increasing availability of industrial systems through data stream mining, Computers \& Industrial Engineering 60 (2011) 195-205.

[37] R. Yu, B. Iung, H. Panetto, A multi-agents based E-maintenance system with casebased reasoning decision support, Engineering Applications of Artificial Intelligence 16 (4) (2003) 321-333.

[38] E. Plaza, L. Mc Ginty, Distributed case-based reasoning, The knowledge Engineering Review 20 (3) (2005) 261-265

[39] J. Sowa, Conceptual Structures: Information Processing in Mind and Machine. The Systems Programming Series (Hardcover), Addison-Wesley Longman Publishing Co., Inc, Boston, MA, USA, 1984p. 481.

[40] A. Borgida, On the relative expressiveness of description logics and predicate logics, Artificial Intelligence 82 (1996) 353-367.

[41] H. Yao, L. Etzkorn, Automated conversion between different knowledge representation formats, Knowledge-Based Systems 19 (6) (2006) 404-412.

[42] I. Horrocks, P.F. Patel-Schneider, S. Bechhofer, D. Tsarkov, OWL rules: a proposal and prototype implementation, Web Semantics: Science, Services and Agents on the World Wide Web 3 (1) (2005) 23-40.

[43] N. Shadbolt, W. Hall, T. Berners-Lee, The semantic web revisited, IEEE Intelligent Systems 21 (3) (2006) 96-101.

[44] R. Dieng, S. Hug, MULTIKAT, a tool for comparing knowledge from multiple experts, in: ICCS'98, Montpellier, LNAI 1453, (1998), pp. 139-153.

[45] P. Hitzler, H. Scharfe, Conceptual Structures in Practice, 1st edition, Chapman and Hall/CRC, 2009p. 425 ISBN-10: 1420060627. ISBN-13: 978-1420060621.

[46] J.F. Sowa, J.A. Zachman, Extending and formalizing the framework for information systems architecture, IBM Systems Journal 31 (3) (1992) 590-616.

[47] B. Léger, O. Naud, Experimenting statecharts for multiple experts knowledge elicitation in agriculture, Expert Systems with Applications 36 (8) (2009) 1129611303.

[48] J.F. Sowa, Chapter 5: conceptual graphs. Foundations of artificial intelligence, vol 3, in: F. van Harmelen, V. Lifschitz, B. Porter (Eds.), Handbook of Knowledge Representation, Elsevier, 2008, pp. 213-237.

[49] B. Kamsu Foguem, T. Coudert, L. Geneste, C. Beler, Knowledge formalization in experience feedback processes: an ontology-based approach, Computers in Industry 59 (7) (2008) 694-710.

[50] T.R. Gruber, Toward principles for the design of ontologies used for knowledge sharing, International Journal of Human-Computer Studies $43(4 / 5)(1995$ 907-928.

[51] R. Lambiotte, M. Ausloos, Collaborative tagging as a tripartite network, International Conference on Computational Science (3) (2006) 1114-1117.

[52] T.R. Gruber, Ontology of folksonomy: a mash-up of apples and oranges, International Journal on Semantic Web and Information Systems 3 (2007) 1-11.

[53] F. Dotsika, Uniting formal and informal descriptive power: reconciling ontologies with folksonomies, International Journal of Information Management 29 (5) (2009) 407-415.

[54] J.-F. Baget, M.-L. Mugnier, Extensions of simple conceptual graphs: the complexity of rules and constraints, Journal of Artificial Intelligence Research (JAIR) 16 (2002) 425-465.

[55] J.-F. Baget, M. Leclère, M.-L. Mugnier, E. Salvat, Extending decidable cases for rules with existential variables, in: Proceedings of the 21st International Joint Conference on Artificial Intelligence (IJCAI'09), 2009, pp. 677-682.

[56] J.-F. Baget, M. Leclère, M.-L. Mugnier, E. Salvat, On rules with existential variables: walking the decidability line, Artificial Intelligence $175(9 / 10)$ (2011) 1620-1654

[57] R. Dieng-Kuntz, D. Minier, M. Ruzicka, F. Corby, O. Corby, L. Alamarguy, Building and using a medical ontology for knowledge management and cooperative work in a health care network, Computers in Biology and Medicine 36 (7/8) (2006) 871-892.

[58] B. Kamsu-Foguem, Knowledge-based support in non-destructive testing for health monitoring of aircraft structures, Advanced Engineering Informatics (ADVEI) 26 (4) (2012) 859-869. 
[59] T. Denœux, Conjunctive and disjunctive combination of belief functions induced by nondistinct bodies of evidence, Artificial Intelligence $172(2 / 3)(2008)$ 234-264.

[60] J. Lee, M. Ghaffari, S. Elmeligy, Self-maintenance and engineering immune systems: towards smarter machines and manufacturing systems, Annual Reviews in Control 35 (1) (2011) 111-122.

[61] O.V. Thorsen, M. Dalva, A survey of faults on induction motors in offshore oil industry, petrochemical industry, gas terminals, and oil refineries, IEEE Transaction on Industry Applications (IAS) 31 (5) (1995) 1186-1196.

[62] P. Choe, M.R. Lehto, H.J. Park, J. Allebach, A query-based cross-language diagnosis tool for distributed decision making support, Computers \& Industrial Engineering 57 (2009) 37-45.

[63] O. Carloni, M. Leclère, M.-L. Mugnier, Introducing reasoning into an industrial knowledge management tool, Applied Intelligence 31 (3) (2009) 211-224.

[64] S.E. Brossette, A.P. Sprague, W.T. Jones, S.A. Moser, A data mining system for infection control surveillance, Methods of Information in Medicine $39(4 / 5)$ (2000) 303-310, 2000.

[65] S.E. Brossette, P.A. Hymel Jr., Data mining and infection control, Clinics in Laboratory Medicine 28 (1) (2008) 119-126.

[66] F. Beaudouin, B. Munier, A revision of industrial risk management: decisions and experimental tools in risk business, Risk and Decision Analysis 1 (2009) 3-20. , http://dx.doi.org/10.3233/RDA-2008-0001 (IOS press).

[67] C. Sanin, E. Szczerbicki, Using set of experience in the process of transforming information into knowledge, International Journal of Enterprise Information Systems 2 (2) (2006) 45-62.

[68] C. Sanin, C. Toro, J. Vaquero, E. Szczerbicki, J. Posada, Implementing decisional DNA in industrial maintenance by a knowledge SOUPA extension, Systems Science 33 (2007) 61-68.

[69] A. Avizienis, J.-C. Laprie, B. Randell, C. Landwehr, Basic concepts and taxonomy of dependable and secure computing, IEEE Transactions on Dependable and Secure Computing 1 (1) (2004) 11-33.

[70] P. Potes Ruiz, B. Kamsu-Foguem, D. Noyes, Knowledge reuse integrating the collaboration from experts in industrial maintenance management, Knowledge-Based Systems, http://dx.doi.org/10.1016/j.knosys.2013.06.005.

[71] B. Kamsu-Foguem, G. Tchuenté-Foguem, L. Allart, Y. Zennir, C. Vilhelm, H. Mehdaoui, D. Zitouni, H. Hubert, M. Lemdani, P. Ravaux, User-centered visual analysis using a hybrid reasoning architecture for intensive care units, Decision Support Systems 54 (1) (2012) 496-509.

[72] H. Jabrouni, B. Kamsu-Foguem, L. Geneste, C. Vaysse. Analysis reuse exploiting taxonomical information and belief assignment in industrial problem solving. Computers in Industry, 2013, in press.

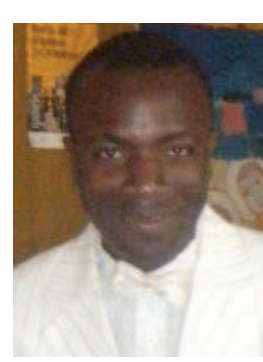

Dr. Bernard Kamsu-Foguem is currently a tenured Associate Professor at the National Engineering School of Tarbes (ENIT) of National Polytechnic Institute of Toulouse (INPT) and leads his research activities in the Production Engineering Laboratory (LGP) of ENIT-INPT, a research entity (EA1905) of the University of Toulouse. He has a Master's in Operational Research, Combinatorics and Optimisation (2000) from National Polytechnic Institute of Grenoble, and a $\mathrm{PhD}$ in Computer Science and Automatic (2004) from the University of Montpellier 2. He got the "accreditation to supervise research" (abbreviated HDR) from INPT in 2013, reflecting a consistent research and typically around 15-20 publications in peer reviewed journals. In ENIT, his main courses are oriented on artificial intelligence methods, Ontology engineering, information systems, knowledge management and visual analysis in Human-computer interaction. His current research work concerns the focuses on Knowledge Representation and Reasoning, Data mining (the analysis step of the "Knowledge Discovery in Databases" process) and Knowledge Management for Collaboration and Decision Support. His articles propose methodologies and representations that are related to Semantic-based Information and Engineering Systems with particular emphases both on knowledge and engineering applications (e.g. quality, industrial maintenance, construction and telemedicine).

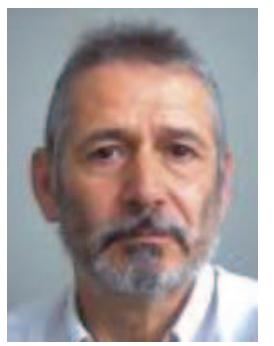

Pr. Daniel Noyes is professor at the National Engineering School of Tarbes of National Polytechnic Institute of Toulouse (ENIT-INPT). He received his Speciality Doctorate degree from the Toulouse Paul Sabatier University in 1975, and his Docteur ès-Sciences degree from the Toulouse National Polytechnic Institute in 1987. In ENIT, his main courses are oriented on tools and methods for the design and control of production systems including dependability concepts and risk analysis principles. He was director of the "Production Engineering Research Laboratory" of ENIT-INPT for 10 years (2001-2011) whose activities are dealing with mechanical engineering and industrial engineering. His current research work concerns the dependability of the production systems, risk management, e-maintenance and collaborative decision making, and he is the author or co-author of more than one hundred papers for international and national journals and conferences. 